Journal of Engineering and Applied Sciences 15 (7): 1709-1716, 2020

ISSN: 1816-949X

(C) Medwell Journals, 2020

\title{
Increasing Growth and Yield of Sweet Basil and Holy Basil by Application of Far-Red Radiation for Indoor Horticulture
}

\author{
Napat Watjanatepin and Patcharanan Sritanauthaikorn \\ Solar Energy Research Technology Transfer Center, Faculty of Engineering and Architecture, \\ Rajamangala University of Technology Suvarnabhumi, 7/1 Nonthaburi1 Road, \\ 11000 Nonthaburi, Thailand
}

\begin{abstract}
The objective of this study is to investigate the interaction of R, B and FR from phosphor-converted LED on the growth and yield of the sweet basil and holy basil. Seedlings were grown in the chamber with a continuous supply of $200 \mu \mathrm{molm}^{-2} \mathrm{sec}^{-1}$ PPFD of R and B. Several ratios were applied as R:B.3.5 and 7.0 without FR and R:B.3.5 with FR $50 \mu \mathrm{molm}^{-2} \mathrm{sec}^{-1}$. The photo period was $16 / 8 \mathrm{~h}$. The results found that R:B.3.5 with FR50 significantly increased the growth rate by $49-114 \%$, the plant height by $64-137 \%$, the stem diameter by $20-25 \%$ and the total fresh weight by $98-181 \%$ of the crops. R:B.3.5 with FR50 also significantly increased the average leaf area by $59-85 \%$ for the holy basil but not in the sweet basil and increased the total dry weight by $110-253 \%$ of the sweet basil but not in the holy basil. Additionally, no effects on the leaf thickness of the crops were observed. R:B.7 without FR had the trend to promote the growth of leaf and stem and total fresh weight of the crops than R:B.3.5 without FR. Moreover, the combination of FR with the R and B light could increase the leaf expansion, stem length whole plant photosynthesis and total fresh and dry weight of the sweet basil and holy basil.
\end{abstract}

Key words: Phosphor converted-LEDs, basil, far-red light, leaf expansion, growth rate

\section{INTRODUCTION}

The sweet basil and the holy basil are commonly used in most Thai kitchen because their properties are appropriate for alternative medicine, aromatic and good herbal taste. Thai people conveniently bought them from a supermarket but these merchandises could well receive the chemical contaminations that may have negative effects on their health to the extent of possibly causing cancer. Thai people currently turn to consume the organic vegetable or to grow vegetables to eat on their own. However, in the urban environment, people tend to live in high density homes such as apartments which free space and natural light for the plants are limited in the room.

Indoor horticulture is the key to solve this problem. How can people plant the organic vegetable in their room? What kind of lighting supply would be convenient and perfect for the organic plants? One traditional answer is to use $1 \mathrm{~m}^{2}$ of area for planting in the room with the efficient artificial light by using a vertical pot or a vertical hydroponic bed with the artificial light. Most popular indoor horticultural lighting systems are the LEDs. Many types/techniques of the LED horticultural light are Red (R)-Blue (B) LED, red-blue plus UV and Far-Red (FR), mixed-color (RGB) LED and white LED (Watjanatepin et al., 2018). The FR light regulates the phytochrome-mediated morphological and physiological plant responses and increases leaves and total biomass of the high-wire tomato (Zhang et al., 2019). In addition, the FR light also increases total leaves area and shoot dry weight of geranium and snapdragon (Park and Runkel, 2017). Additionally, the FR light promotes flowering in petunia, especially, under a lower light intensity (Park and Runkel, 2018) and red-blue with FR increased the shoot fresh weight, total biomass and leaves length of basil (Meng and Runkle, 2017).

Currently, phosphor-converted horticultural LED (pcH-LED) are well known in the horticultural light industry, for example, LUXEON horticultural LED (Lumiled, 2017) or the full spectrum light of horticultural white-based from SAMSUNG and CREE. The pcH-LEDs could produce the light spectrum that covers the Photosynthetic Active Radiation (PAR) wavelength (400$700 \mathrm{~nm})$ as well as adding the FR (700-800 nm) radiation. Therefore, this option is very interesting because it is possible to use a single chip of pcH-LED for generating the $\mathrm{B}, \mathrm{R}$ and $\mathrm{FR}$ radiation. This means that it is convenient and easy to apply to the real indoor horticultural environment.

The primary objective of this study was to investigate the growth characteristic and the yield of the sweet basil and the holy basil under the pcH-LED (R:B with FR) compared to R:B without FR. The researchres provided

Corresponding Author: Napat Watjanatepin, Solar Energy Research Technology Transfer Center,

Faculty of Engineering and Architecture, Rajamangala University of Technology Suvarnabhumi,

7/1 Nonthaburi1 Road, 11000 Nonthaburi, Thailand 
the $\mathrm{R}: \mathrm{B}$ ratio that is equal to $\mathrm{R}: \mathrm{B}$ ratio of $\mathrm{pcH}-\mathrm{LED}$ $(\mathrm{R}: \mathrm{B}=3.5$ by measured with $\mathrm{FR})$ and $\mathrm{R}: \mathrm{B}=3.5$ and $\mathrm{R}: \mathrm{B}=7.0$ without FR. The secondary aim is to discuss about the specific FR radiation that is emitted from the phosphor-converted LED.

\section{MATERIALS AND METHODS}

Plant and growth conditions: Plants in this study included the sweet basil (Ocimum basilicum Linn) and the holy basil (Ocimum tenuiflorum L.). After incubating the plant seeds at $4^{\circ} \mathrm{C}$ on moistened sponge for 5 days, the germinated seeds were transferred into the plastic pots at one seed per one pot. Each pot was contained with loamy soil, compost, paddy husk charcoals and coconut dust in the same quantity and placed in the growth chamber in the temperature control room. The temperature was maintained at $30 / 23^{\circ} \mathrm{C}$ (day/night) and the humidity was at $50-75 \%$. Each group consisted of 3 pots of the sweet basil and 3 pots of the holy basil. Thirty milliliter of tap water was supplied to each pot once a day in the morning. The plants were irradiated with three treatments with different spectral of light that will be described in the next section. The researchers focused on different growth characteristic on the stem system and not the root system because the plants were grown in the soil which difficultly made root separation from the soil and the root might be damaged easily.

Treatments and LED artificial light: PPFD value presented to all experiments is $200 \pm 5 \mu \mathrm{molm}^{-2} \mathrm{sec}^{-1}$, the light and dark hour was 14/10. The harvesting time is 42 Days After Sowing (DAS). The researchers designed the artificial light in three different techniques including R:B.7-LED, R:B.3.5-LED and R:B.3.5+FR50 (pcH-LED).

\section{R:B.7-LED}

Experiment 1: A custom-made R:B $=7$ (R:B.7) LED light was a light source. The input voltage was $220 \mathrm{~V} 50 \mathrm{~Hz}$. The $24 \mathrm{~V} 300 \mathrm{~W}$ of LED drivers with dimming control were used to drive the group of $\mathrm{R}$ and $\mathrm{B}$ LED. The dimension was $45 \mathrm{~cm}$ width $\times 45 \mathrm{~cm}$ length. The R:B LED light consisted of two color of narrow band spectral LED which amounted in the 42 pcs of $446 \mathrm{~nm}$ red LEDs and 28 pcs of $645 \mathrm{~nm}$ of blue LEDs. The total power was $152.5 \mathrm{~W}$. The spectrum distribution of the R:B LED light was a dash line as shown in Fig. 1. The measurement of the spectrum distribution of R:B could declare the total PPFD to be about $200.18 \mu \mathrm{molm}^{-2} \mathrm{sec}^{-1}$ (measured R:B = 6.95, $\mathrm{R}=172.12, \mathrm{G}=3.27, \mathrm{~B}=24.77$ and $\mathrm{FR}=3.1 \mu \mathrm{molm}^{-2} \mathrm{sec}^{-1}$ ).

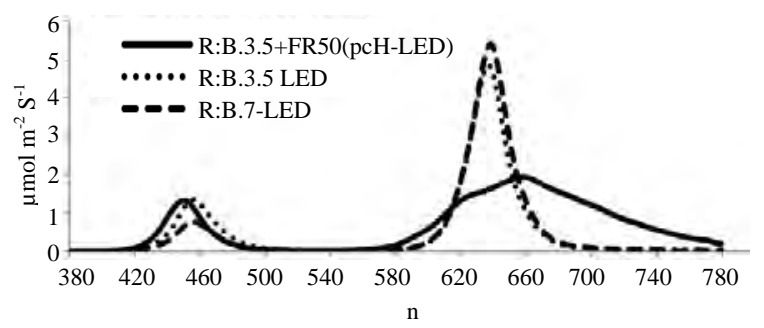

Fig. 1: Spectral distribution of the light treatment of the first experiment group (R:B.7-LED), the second experiment group (R:B.3.5-LED) and the third experiment group R:B.3.5+FR50 (pcH-LED). They are measured by the Spectroradiometer "Lighting Passport Pro Essence”.

\section{R:B.3.5-LED}

Experiment 2: Using the same custom design, the authors adjusted the R:B ratio close to 3.5. The total power was $160.7 \mathrm{~W}$, the spectrum distribution was a dot line as shown in Fig. 1 and the total PPFD was 198.24 $\mu_{\text {molm }}^{-2} \mathrm{sec}^{-1}$ (measured $\mathrm{R}: \mathrm{B}=3.53, \mathrm{R}=151.52$, $\mathrm{G}=3.74, \mathrm{~B}=42.96$ and $\mathrm{FR}=3.00 \mu \mathrm{molm}^{-2} \mathrm{sec}^{-1}$ ).

\section{R:B.3.5+FR50(pcH-LED)}

Experiment 3: The pcH-LED Model YXO-GLC-8001: LED chip dimension was $78 \times 44 \times 1.6 \mathrm{~mm}$. The spectrum distribution was $380-840 \mathrm{~nm}$. LED chips were from Bridgelux, power was $20 \mathrm{~W}$ (Shenzhen Yuxinou Technology Co., Ltd., China). This design was also custom-made and it consisted of 6 modules of LED connected in parallel. The total power was $108.5 \mathrm{~W}$. It was installed on the aluminum heat sink. The total light area was $45 \times 27.5 \mathrm{~cm}$. The supply voltage was $220 \mathrm{~V}$ $50 \mathrm{~Hz}$ with dimming controller that could supply to the LED chip without the need of the external LED driver. The spectrum distribution was a dark line as shown in Fig. 1. The measurement of the spectrum of pcH-LED could declare the total PPFD to be $200.79 \mu \mathrm{mol} . \mathrm{m}^{-2} . \mathrm{sec}^{-1}$ $(\mathrm{R}: \mathrm{B}=3.5, \mathrm{R}=149, \mathrm{G}=9.9, \mathrm{~B}=42.2$ and $\mathrm{FR}=49.6$ or $\approx$ $\left.50 \mu \mathrm{molm}^{-2} \mathrm{sec}^{-1}\right)$.

Measurements and calculation: The PPFD spectrum distribution and photosynthetic photon flux of the light sources were measured by the Spectroradiometer Lighting Passport Pro Essence (Asensetek Incorporation, Taiwan). The growth and development of the stem and leaf of the sweet basil and the holy basil were investigated by acquiring the plant height, the stem diameter and the leaf number. These parameters were measured and recorded every week after DAS. The Growth Rate (GR) was determined during the lag phase to exponential growth between the first week and the sixth week by measuring the plant height. The growth rate, GR is: 


$$
\mathrm{GR}=\frac{\mathrm{S}_{2}-\mathrm{S}_{1}}{\mathrm{~T}} \quad \mathrm{~cm} / \mathrm{d}
$$

Where:

$\mathrm{S}_{1}$ : The first measurement

$\mathrm{S}_{2}$ : The second measurement

$\mathrm{T}$ : The number of days between each measurement (Taiz and Zeiger, 2010)

The plant height defined the height measurement of the main plant stem from the border of the container to the top of the main plant stem $(n=3)$. The leaves were counted and recorded for each plant $(n=3)$. The leaf area per a leaf and leaf thickness were measured at the forty-sec day of the treatment by selecting the four best representative leaves of one plant of each group. From the terminal bud, the researchers collected four leaves of the second node and the third node $(n=4)$. The leaf area was measured by digital image analysis. The stem diameter was measured by a digital vernier caliper, 0-200 mm (Mitutoyo Crop., Kanagawa, Japan). The fresh weight and dry weight of the plants were investigated and measured by a digital weight scale with the range of 0.01-500 g (TWK, China). The weight progressed by first cutting the leaves and stem of plants $(n=2)$ and putting them in the oven at $70^{\circ} \mathrm{C}$ for $48 \mathrm{~h}$. Finally, the dried leaves and stem were placed in a desiccator to cool to room temperature and weighted.

Statistical analyses: Plant samples will be taken from six plants of each group (3 of the sweet basil and 3 of the holy basil) for the investigation of the leaf number, leaf area, stem diameter, fresh weight and dry weight. The significant difference were analyzed by ANOVA ( $\mathrm{p}=$ 0.05). The mean separations were analyzed by the Duncan's New Multiple Range Test ( $p=0.05)$. The IBM SPSS statistics was used for analysis.

\section{RESULTS AND DISCUSSION}

\section{Growth and development of leaf and stem}

Sweet basil: After 42 days of experiments, the sweet basil under R:B.3.5+FR50 (pcH-LED) displayed the highest stem development with the plant high at $29.53 \mathrm{~cm}$ (Fig. 2a). During a 3 week period, the sweet basil showed a low plant growth rate. During a 6 week period, these plants indicated the highest growth rate. The sweet basil under R:B.3.5 and R:B.7 exhibited a low growth rate than R:B.3.5+FR50 (Fig. 2a). The sweet basil under R:B.7 presented the lowest plant height. In accordance with the leaf development of the sweet basil under R:B.3.5+FR50, the average leaf number per plant was highest at 74.33 leaves (Fig. 2b). The leaf number of the sweet basil under R:B.3.5 was lower than R:B.7. The leaf number of sweet basil under all treatments displayed the highest development on the fifth to 6th week of cultivation. The experimental results indicated that the effects of the FR light on the sweet basil, when compared to the statistical analysis, displayed the significant difference $(\mathrm{p}<0.05)$. The plant height under R:B.3.5+FR50 with the maximum height at $29.53 \mathrm{~cm}$, showed significant difference $(\mathrm{p}<0.05)$ from the R:B.3.5 and R:B.7 (18.00 and 15.87 $\mathrm{cm}$, respectively) as summarized in Table 1 . The sweet basil under R:B.3.5+FR50 increased the plant height by 64\% (R:B.3.5) and 86\% (R:B.7).

The average GR of the sweet basil, when compared to the statistical analysis, demonstrated a significant difference $(\mathrm{p}<0.05)$. The highest GR under R:B.3.5+FR50 is $0.82 \mathrm{~cm} / \mathrm{d}$ which is significantly different $(\mathrm{p}<0.05)$ to R:B.3.5 and R:B.7 (0.47 and $0.41 \mathrm{~cm} / \mathrm{d}$, respectively, Table 1). The sweet basil under R:B.3.5+FR50 increased the GR by $74 \%$ (R:B.3.5) and 107\% (R:B.7).

The average stem diameter of the sweet basil, when the average is used for the statistical analysis was found to be significantly different $(\mathrm{p}<0.05)$. The stem diameter under R:B.3.5+FR50 was the highest at $3.67 \mathrm{~mm}$ but did not show a significant difference $(\mathrm{p}<0.05)$ with under R:B.7 at $2.98 \mathrm{~mm}$ (Table 1). However, the value was significantly different $(\mathrm{p}<0.05)$ to R:B.3.5 $(2.46 \mathrm{~mm})$. The sweet basil under R:B.3.5+FR50 increased the stem diameter by 49\% (R:B.3.5) and 23\% (R:B.7).

The average leaf number of the sweet basil, when the average is compared by the statistical analysis, exhibited significant difference $(\mathrm{p}<0.05)$. The number of the leaves under R:B.3.5+FR50 has a maximum number at 74.33 but did not show a significant difference $(\mathrm{p}<0.05)$ with under R:B.7 (59.00). Nevertheless, this value indicated significant difference $(\mathrm{p}<0.05)$ with R:B.3.5 with the leaf number of 36.00 (Table 1). Sweet basil under R:B.3.5+FR50 increased average leaf number by 106\% (R:B.3.5) and 25\% (R:B.7).

The average leaf thickness and the average leaf area of the sweet basil under all treatments when compared statistically were found not to be significantly different $(\mathrm{p}<0.05)$.

In summary, the sweet basil under R:B.3.5+FR50 demonstrated the highest growth and development in plant height, GR, stem diameter and leaf number (Fig. 3a) as well as displaying values with statistically significant difference $(\mathrm{p}<0.05)$ when compared with those from R:B.3.5 and R:B.7. However, the leaf thickness and leaf area of sweet basil under all treatments did not show any significant difference $(\mathrm{p}<0.05)$.

Holy basil: Figure 4 showed the experiment results of growth rate, development and leaf number of the holy basil under different light quality. The holy basil under R:B.3.5+FR50 showed the highest stem development as $23.53 \mathrm{~cm}$ high (Fig. 3b). During the first 3 weeks, the holy basil showed low plant growth rate and from the last 

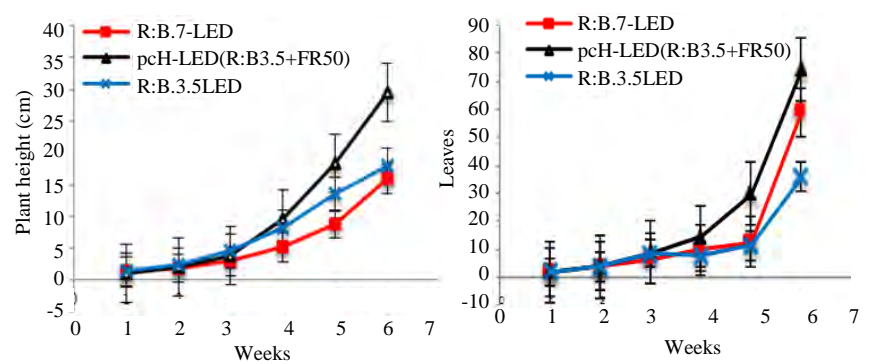

Fig. 2: The height of the plants and the leaf development of the sweet basil during a six week period of investigation (a) The plant height and (b) The number of the leaves

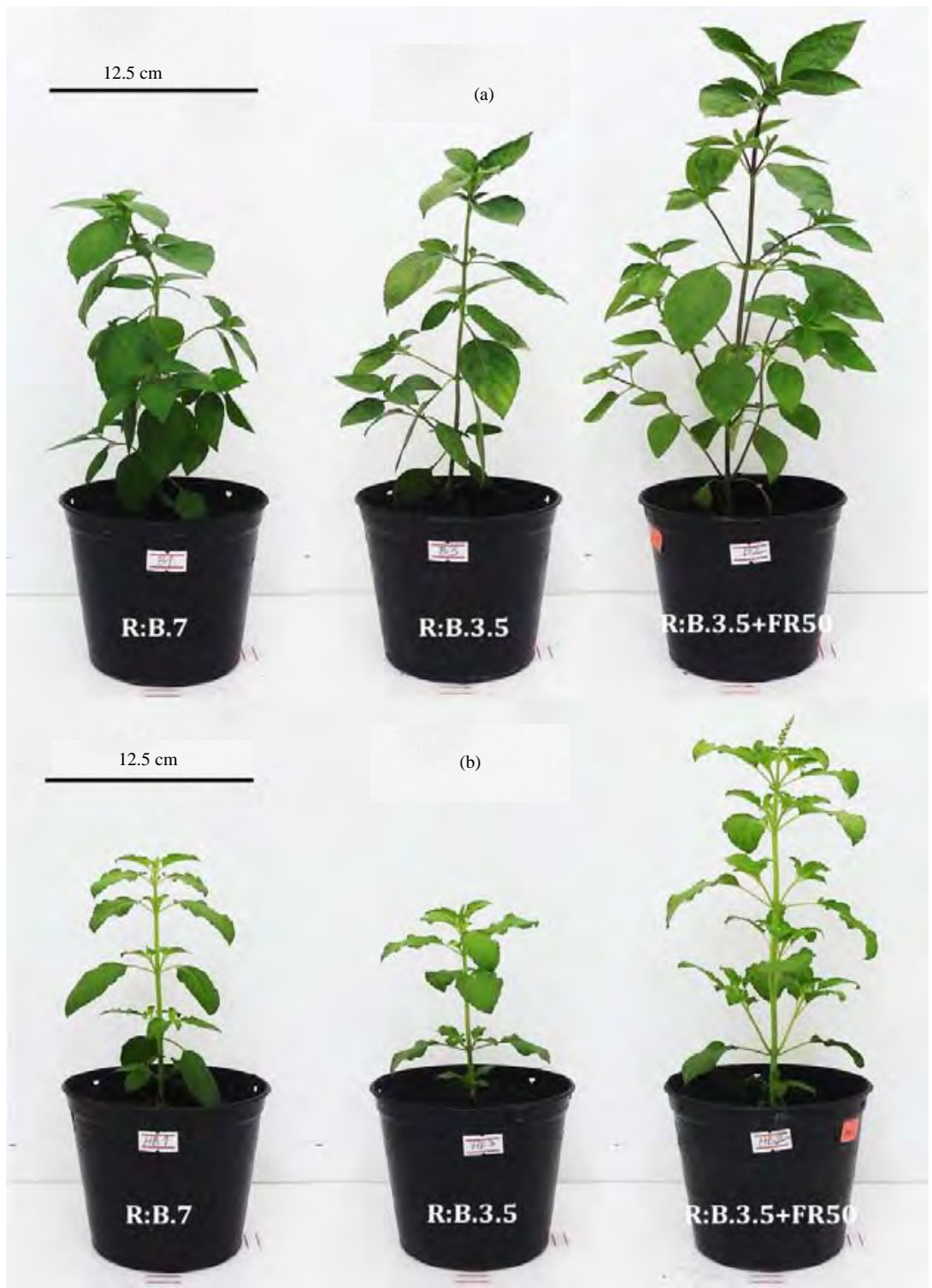

Fig. 3: Comparative growth and development of (a) Sweet basil and (b) Holy basil under R:B.7-LED, R:B.3.5 and R:B.3.5+FR50(pcH-LED) after 42 DAS

3 weeks, the plant had the highest growth rate. The holy basil under R:B.3.5 and R:B.7 exhibited a lower plant growth rate than R:B.3.5+FR50 (Fig. 4a). The plant height curves indicated in the same trend. In accordance 


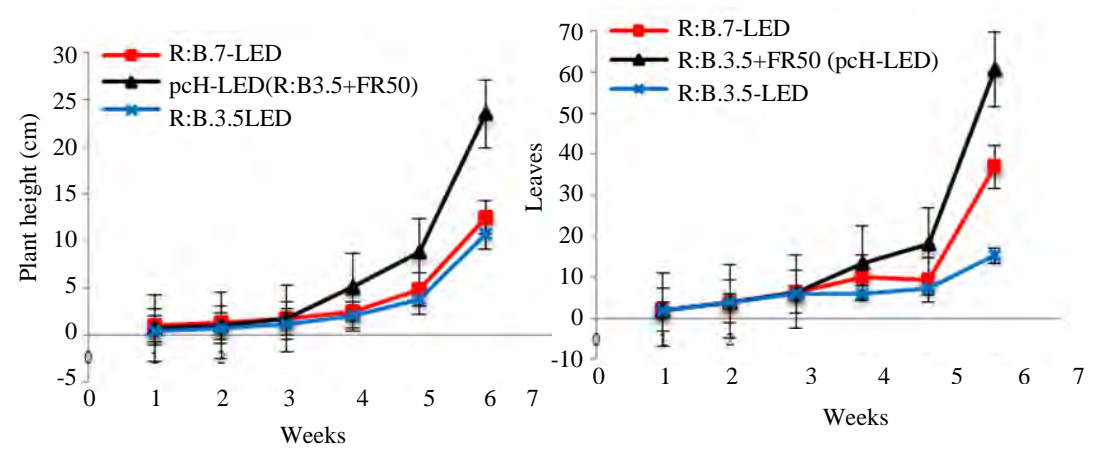

Fig. 4: The height of the plants and the leaf development of the holy basil during a 6 week period of investigating, a) The plant height and $b$ ) The number of the leaves

Table 1: Average growth and development of stem, leaf, plant height and growth rate of sweet basil at 42 DAS

\begin{tabular}{llccccc}
\hline LED & Plant height $(\mathrm{cm})$ & Growth rate $(\mathrm{cm} / \mathrm{d})$ & Stem diameter $(\mathrm{mm})$ & Leaf number $($ leaf $)$ & Leaf thickness $(\mathrm{mm})$ & Leaf area $\left(\mathrm{cm}^{2}\right)$ \\
\hline R:B.7 & $15.87 \pm 4.53^{\mathrm{b}}$ & $0.41 \pm 0.12^{\mathrm{b}}$ & $2.98 \pm 0.57^{\mathrm{b}}$ & $59.00 \pm 19.67^{\mathrm{ab}}$ & $0.43 \pm 0.05$ & $14.42 \pm 1.67$ \\
R:B.3.5 & $18.00 \pm 2.64^{\mathrm{b}}$ & $0.47 \pm 0.77^{\mathrm{b}}$ & $2.46 \pm 0.45^{\mathrm{b}}$ & $36.00 \pm 4.00^{\mathrm{b}}$ & $0.46 \pm 0.05$ & $13.09 \pm 1.29$ \\
R:B.3.5+FR50 & $29.53 \pm 3.19^{\mathrm{a}}$ & $0.82 \pm 0.09^{\mathrm{a}}$ & $3.67 \pm 0.51^{\mathrm{a}}$ & $74.33 \pm 8.14^{\mathrm{a}}$ & $0.46 \pm 0.02$ & $14.02 \pm 2.79$ \\
F-test & $*$ & $*$ & $*$ & $*$ & ns & ns \\
\hline
\end{tabular}

*: Significant difference $(\mathrm{p}<0.05)$ ns: No. significant; difference $(\mathrm{p}<0.05)$; ab: Followed by the same letter in each column are not significantly different $(\mathrm{p}<0.05)$

Table 2: Average growth and development of stem, leaf, plant height and growth rate of holy basil at 42 DAS

\begin{tabular}{lcccccc} 
LED & Plant height $(\mathrm{cm})$ & Growth rate $(\mathrm{cm} / \mathrm{d})$ & Stem diameter $(\mathrm{mm})$ & Leaf number (leaf) & Leaf thickness $(\mathrm{mm})$ & Leaf area $\left(\mathrm{cm}^{2}\right)$ \\
\hline R:B.7 & $12.50 \pm 5.76^{\mathrm{b}}$ & $0.33 \pm 0.17^{\mathrm{b}}$ & $2.72 \pm 0.21^{\mathrm{b}}$ & $37.00 \pm 11.26^{\mathrm{ab}}$ & $0.40 \pm 0.03$ & $8.58 \pm 0.98^{\mathrm{b}}$ \\
R:B.3.5 & $10.76 \pm 2.09^{\mathrm{b}}$ & $0.29 \pm 0.05^{\mathrm{b}}$ & $2.61 \pm 0.13^{\mathrm{b}}$ & $15.33 \pm 3.05^{\mathrm{b}}$ & $0.35 \pm 0.07$ & $7.22 \pm 1.07^{\mathrm{b}}$ \\
R:B.3.5+FR50 & $23.53 \pm 1.69^{\mathrm{a}}$ & $0.65 \pm 0.05^{\mathrm{a}}$ & $3.26 \pm 0.10^{\mathrm{a}}$ & $60.66 \pm 21.58^{\mathrm{a}}$ & $0.40 \pm 0.06$ & $13.68 \pm 2.50^{\mathrm{a}}$ \\
F-test & $*$ & $*$ & $*$ & $*$ & ns & $*$
\end{tabular}

*: Significant difference $(\mathrm{p}<0.05)$ ns: No. significant difference $(\mathrm{p}<0.05)$ ab: Followed by the same letter in each column are not significantly different at $\mathrm{p}<0.05$

with the leaf development of the holy basil under R:B.3.5+FR50, the average leaf number per plant was highest at 60.66 leaves (Fig. 4b). The leaf number of the holy basil under R:B.3.5 was still lower than R:B.7. The leaf number of holy basil under R:B.7, R:B.3.5 and R:B.3.5+FR50 displayed the highest development on the 5-6th week of cultivation.

Table 2 indicated that the effect of FR light to growth and development of the holy basil when compared with the statistical analysis, demonstrated the significant difference $(\mathrm{p}<0.05)$. The plant height under R:B.3.5+FR50 with the maximum height at $23.53 \mathrm{~cm}$, showed a significant difference $(\mathrm{p}<0.05)$ from the R:B.7 and R:B.3.5 (12.50 and $10.76 \mathrm{~cm}$, respectively).

The average GR of the holy basil when compared with the statistical analysis, showed a significant difference $(\mathrm{p}<0.05)$. The GR under R:B.3.5+FR50 with the highest GR value at $0.65 \mathrm{~cm} / \mathrm{d}$ (Table 2), showed significant difference $(\mathrm{p}<0.05)$ to R:B.7 and R:B.3.5 (0.33 and $0.29 \mathrm{~cm} / \mathrm{d}$, respectively). The holy basil under R:B.3.5+FR50 increased GR by 124 and $49 \%$ of R:B3.5 and R:B.7, respectively. The average stem diameter of the holy basil, when compared with the statistical analysis, displayed a significant difference $(\mathrm{p}<0.05)$. The stem diameter under R:B.3.5+FR50 was a highest diameter at $3.26 \mathrm{~mm}$ and showed a significant difference $(\mathrm{p}<0.05)$ from the values under R:B.7 and R:B.3.5 (2.72 and 2.61 $\mathrm{mm}$, respectively, Table 2). The holy basil under R:B.3.5+FR50 increased the stem diameter by 25 and $20 \%$ of R:B3.5 and R:B.7.

The average number of the leaves of the holy basil when compared with the statistical analysis was found to be significantly different $(\mathrm{p}<0.05)$. The leaf number under R:B.3.5+FR50 was the highest value at 60.66 but did not show a significant difference $(\mathrm{p}<0.05)$ and under R:B.7 with the value of 37.00 . However, the significant difference $(p<0.05)$ was observed when compared to R:B.3.5 (15.33, Table 2). Holy basil under R:B.3.5+FR50 increased leaf number by 259 and 64\% of R:B3.5 and R:B.7.

The average leaf thickness of holy basil when compared with the statistical analysis was found not to be significantly different $(\mathrm{p}<0.05)$. The leaf thickness under R:B.3.5+FR50 and R:B.7 has shown tendency to highest $0.40 \mathrm{~mm}$ equally, average leaf thickness under R:B.3.5 show the lowest at $0.35 \mathrm{~mm}$ (Table 2). The average leaf area of the holy basil when compared with the statistical 
J. Eng. Applied Sci., 15 (7): 1709-1716, 2020

Table 3: Average yield of the sweet basil at 42 DAS

\begin{tabular}{|c|c|c|c|c|c|c|}
\hline \multirow[b]{2}{*}{ LED } & \multicolumn{2}{|c|}{ Fresh weight(g/plant) } & \multicolumn{4}{|l|}{ Dry weight(g/plant) } \\
\hline & Leaf & Stem & Total(Leaf+Stem) & Leaf & Stem & Total (Leaf+Stem) \\
\hline R:B.7 & $6.20 \pm 0.35^{\mathrm{b}}$ & $2.51 \pm 0.06^{\mathrm{b}}$ & $8.71 \pm 0.29^{b}$ & $0.92 \pm 0.06^{\mathrm{ab}}$ & $0.04 \pm 0.01^{\mathrm{b}}$ & $1.36 \pm 0.05^{\mathrm{b}}$ \\
\hline R:B.3.5 & $4.12 \pm 0.14^{\mathrm{b}}$ & $1.46 \pm 0.13^{\mathrm{b}}$ & $5.58 \pm 0.27^{b}$ & $0.52 \pm 0.21^{\mathrm{b}}$ & $0.28 \pm 0.02^{\mathrm{b}}$ & $0.81 \pm 0.04^{\mathrm{b}}$ \\
\hline R:B.3.5+FR50 & $10.97 \pm 2.75^{\mathrm{a}}$ & $6.34 \pm 1.14^{\mathrm{a}}$ & $17.31 \pm 3.89^{\mathrm{a}}$ & $1.64 \pm 0.69^{\mathrm{a}}$ & $1.22 \pm 0.36^{\mathrm{a}}$ & $2.86 \pm 1.06^{\mathrm{a}}$ \\
\hline F-test & * & * & * & * & * & * \\
\hline
\end{tabular}

analysis was found to have a significant difference $(p<0.05)$. The leaf area under R:B.3.5+FR50 showed the highest area at $13.68 \mathrm{~cm}^{2}$ as well as showing a significant difference $(\mathrm{p}<0.05)$ with under R:B.7 and R:B.3.5 (8.58 and $7.22 \mathrm{~cm}^{2}$, respectively, Table 2 ). The holy basil under R:B.3.5+FR50 increased the average leaf area by 89 and $59 \%$ of R:B3.5 and R:B.7. In summary, the holy basil under R:B.3.5+FR50 increased the plant height, GR, stem diameter, leaf number and leaf surface area (Fig. 4b). However, the average leaf thickness of the holy basil did not show a significant difference $(\mathrm{p}<0.05)$ under all treatment.

\section{Yields}

Sweet basil: The mean of the yield of the sweet basil under different LED light demonstrated that the leaf weight showed a significant difference $(\mathrm{p}<0.05)$. The leaf fresh weight under R:B.3.5+FR50 indicated the highest yield of $10.97 \mathrm{~g} /$ plant which is significantly different from the sweet basil under R:B.3.5 and R:B.7 (4.12 and $6.20 \mathrm{~g} /$ plant, respectively, Table 3).

The leaf dry weight showed the same trend of the leaf fresh weight. The leaf dry weight under R:B.3.5+FR50 indicated the highest yield of $0.92 \mathrm{~g} /$ plant but did not show any significant difference $(\mathrm{p}<0.05)$ from leaf dry weight under R:B.7 (0.92 g/plant). However, the value exhibited significant difference $(\mathrm{p}<0.05)$ to sweet basil under R:B.3.5 (0.52 g/plant, Table 3).

Stem fresh weight of sweet basil under R:B.3.5+FR50 was the highest at $6.34 \mathrm{~g} /$ plant and also showed a significant difference $(\mathrm{p}<0.05)$ from R:B.7 and R:B.3.5 (2.51 and 1.46 g/plant, respectively, Table 3). In the same way with stem dry weight, the highest stem dry weight of the sweet basil under R:B.3.5+FR50 was highest at $1.22 \mathrm{~g}$. This value showed significant difference $(\mathrm{p}<0.05)$ from R:B.3.5 and R:B.7 (0.28 and 0.04 g/plant, respectively, Table 3 ).

The highest total fresh weight of the sweet basil under R:B.3.5+FR50 was indicated as the highest yield at $17.31 \mathrm{~g} /$ plant and showed significant difference $(\mathrm{p}<0.05)$ from R:B.7 and R:B.3.5 (8.71 and $5.58 \mathrm{~g} / \mathrm{plant}$, respectively). The total dry weight of the sweet basil under this experiment demonstrated the same tendency with the total fresh weight (Table 3).

In summary, the effect of FR at $50 \mu \mathrm{molm}^{-2} \mathrm{sec}^{-1}$ from R:B.3.5+FR50 increased the total fresh weight of the sweet basil by 210 and 98\% (R:B.3.5 and R:B.7). Additionally, the FR at $50 \mu \mathrm{molm}^{-2} \cdot \mathrm{sec}^{-1}$ increased the total dry weight of the sweet basil by 253 and $110 \%$ (R:B.3.5 and R:B.7) which are significantly different $(\mathrm{p}<0.05)$.

Holy basil: The yield of the holy basil under different LED light demonstrated that the leaf fresh weight showed a significant difference $(\mathrm{p}<0.05)$. The leaf fresh weight under R:B.3.5+FR50 indicated the highest weight of $6 \mathrm{~g}$ /plant that differed from the holy basil under R:B.3.5 and R:B.7 (2.43 and 2.45 g/plant, respectively, Table 4).

Statistical results of average leaf dry weight of the holy basil under all treatments were found to be not significantly different $(\mathrm{p}<0.05)$. Trends of leaf dry weight of holy basil under R:B.3.5+FR50 were the highest at $0.54 \mathrm{~g} /$ plant followed by R:B.7 and R:B.3.5 (0.28 and 0.24 g/plant, respectively, Table 4).

Table 4 summarized the stem fresh weight of holy basil under R:B.3.5+FR50 which was the highest value at 3.09 g/plant. This finding showed significant difference $(\mathrm{p}<0.05)$ from R:B.7 and R:B.3.5 (1.13 and $0.80 \mathrm{~g}$ /plant, respectively). However, the stem dry weight of holy basil under all treatments did not show significant difference $(\mathrm{p}<0.05)$. The experimental results showed that the trend of the yield of stem dry weight under R:B.3.5+FR50 was highest at $0.79 \mathrm{~g} /$ plant and higher than under R:B7 and R:B.3.5 (0.41 and 0.32 g/plant, respectively).

The total fresh weight of the holy basil under R:B.3.5+FR50 was indicated to be the highest at $9.09 \mathrm{~g} / \mathrm{plant}$ and showed a significant difference $(\mathrm{p}<0.05)$ from R:B.7 and R:B.3.5-LED (3.58 and 3.23 g/plant, respectively). The total dry weight yield of the holy basil under R:B.3.5+FR50 was the highest at $0.79 \mathrm{~g} /$ plant but did not show any significant difference $(\mathrm{p}<0.05)$ from the total dry weight under R:B7 and R:B.3.5 (0.41 and $0.32 \mathrm{~g} /$ plant, respectively, Table 4).

In summary, the yield of the holy basil indicated by total fresh and dry weight from this experiment could say that the FR radiation from R:B.3.5+FR50 could increase the total fresh weight by 158 and 181\% (R:B.7 and $\mathrm{R}: \mathrm{B} 3.5)$ with significant difference $(\mathrm{p}<0.05)$. The FR radiation can increase the total dry weight of holy basil by 92 and 147\% (R:B.7 and R:B3.5) but was not 
J. Eng. Applied Sci., 15 (7): 1709-1716, 2020

Table 4: Average yield of the holy basil at 42 DAS

\begin{tabular}{|c|c|c|c|c|c|c|}
\hline \multirow[b]{2}{*}{ LED } & \multicolumn{2}{|c|}{ Fresh weight(g/plant) } & \multicolumn{4}{|l|}{ Dry weight(g/plant) } \\
\hline & Leaf & Stem & Total (Leaf+Stem) & Leaf & Stem & Total (Leaf+Stem) \\
\hline R:B.7 & $2.45 \pm 0.53^{\mathrm{b}}$ & $1.13 \pm 0.79^{\mathrm{b}}$ & $3.58 \pm 1.32^{b}$ & $0.28 \pm 0.09$ & $0.13 \pm 0.11$ & $0.41 \pm 0.20$ \\
\hline R:B.3.5 & $2.43 \pm 0.74^{\mathrm{b}}$ & $0.80 \pm 0.11^{\mathrm{b}}$ & $3.23 \pm 0.85^{\mathrm{b}}$ & $0.24 \pm 0.17$ & $0.08 \pm 0.01$ & $0.32 \pm 0.18$ \\
\hline R:B.3.5+FR50 & $6.00 \pm 0.04^{\mathrm{a}}$ & $3.09 \pm 0.24^{\mathrm{a}}$ & $9.09 \pm 0.19^{\mathrm{a}}$ & $0.54 \pm 0.20$ & $0.24 \pm 0.19$ & $0.79 \pm 0.39$ \\
\hline F-test & $*$ & * & * & ns & ns & ns \\
\hline
\end{tabular}

significantly different $(\mathrm{p}<0.05)$. The $\mathrm{R}: \mathrm{B}$ combination light is appropriate to be applied for indoor horticultural applications. The higher R:B ratio could show positive effects for growth development and yield of the sweet basil and the holy basil. The R:B combination with FR increased the growth and yield better than $\mathrm{R}: \mathrm{B}$ without FR. The pcH-LED could emit R+B+FR perfectly. From this study, the researchers could describe the following:

The sweet basil under R:B.3.5+FR50 increased the GR by 75 and $107 \%$ of R:B.3.5 and R:B.7, respectively, as well as increasing the plant height by 64 and $86 \%$ of R:B.3.5 and R:B.7. In accordance with the report of Park and Runkle (2017), the FR radiation (700-800 nm) has major affected on extension growth, length of stem and ultimately the height of plants. Similarly, the FR adding to R:B light at the end of day and FR enriched spectrum indicated that the tomato seedling was taller than without FR.

R:B.3.5+FR50 increased the stem diameter of the sweet basil by 49 and 25\% of R:B.3.5 and R:B.7. This finding confirms to the report of Fallstrom where the tomato seedling growth under R:B with FR showed 3.3\% (Kaiser) and 3.5\% (Emperoidor) thicker stem than seedling grown without FR.

R:B.3.5+FR50 increased the leaves number of the sweet basil by $106 \%$ and 25\% of R:B.3.5 and R:B.7, respectively. Although, the leaves area of the sweet basil under R:B.3.5+FR50 was not significantly different $(\mathrm{p}<0.05)$ from R:B.3.5 and R:B.7 but photosynthetic potential was increased because of the larger total leaves area of the plant (by many leaves number). The photosynthetic rate improved and would affect the promotion of the length of stem, extension growth and total plant biomass (Zhang et al., 2019; Park and Runkel, 2017; Heliospectra, 2019).

The sweet basil under R:B.3.5+FR50 increased the total fresh weight by 210 and $90 \%$ of R:B.3.5 and R:B.7 and increased the total dry weight by 253 and $110 \%$ of R:B.3.5 and R:B.7. This is in accordance to study of Park and Runkle (2017) on snapdragon and geranium under R:B with FR that could increase shoot dry weight by $28-50 \%$. This is further confirmed by Zhang et al. (2019) who provided the study results that the R:B LED (R $640 \mathrm{~nm}, \mathrm{~B} 450 \mathrm{~nm}$ ) in combination with FR $(735 \mathrm{~nm})$ at $43 \mu \mathrm{molm}^{-2} \mathrm{sec}^{-1}$ could increase the total plant biomass of high-wire tomato plants by
16\% better than sole R:B LED (Zhang et al., 2019). Meng and Runkle (2017) reported that the B and R did not influence the biomass of basil. However, adding FR $\left(30 \mu \mathrm{molm}^{-2} \mathrm{sec}^{-1}\right)$ to R:B $\left(90: 90 \mu \mathrm{molm}^{-2} \mathrm{sec}^{-1}\right)$ could increase the shoot fresh and dry weight of basil.

The holy basil under R:B.3.5+FR50 increased the plant height by 118 and 88\% of R:B.3.5 and R:B.7 and increased GR by $124 \%$ of R:B.3.5 and 97\% of R:B.7. This finding is consistent with some study that confirmed FR (700-800 nm) has a major effect on the extension growth and length of stem (Park and Runkle, 2017) by adding FR to $R$ and $B$ at the end of day 30 min or enriched spectrum. Lastly, FR adding in HPS lamp could increase stem length in the early growth of tomato (Hao et al., 2016).

R:B.3.5+FR50 increased the stem diameter of the holy basil by $25 \%$ of R:B.3.5 and 20\% of R:B.7. This is close to the findings of Jiang et al. (2017) where the experimental results of tomato plant under deep red+B+FR increased stem diameter by $17.1 \%$ better than the plants under deep red+B.

The holy basil under R:B.3.5+FR50 increased the average leaf number by 295 and 64\% of R:B.3.5 and R:B.7 and increased average leaf area by $89 \%$ of R:B.3.5 and 59\% of R:B.7. FR light clearly indicated the leaf morphological development, FR light (735 $\mathrm{nm})$ at $43 \mu \mathrm{molm}^{-2} \mathrm{sec}^{-1}$ with R:B produce larger leaf area of tomato when compared to R:B without FR (Zhang et al., 2019). FR (700-800 nm) was an influence on the size of leaves, total leaf area of geranium and snapdragon by $7 \%$. FR light was weakly effective at promoting the photosynthetic reaction but FR promote leaf expansion when the leaf size increased, plant could capture more light and more potential to grow (Park and Runkle, 2017) better than whole-plant photosynthesis (Meng and Runkle, 2017). Adding FR to R:B light could increase the leaf size of lettuce (Black-seeded Simpson) higher than without FR (Heliospectra, 2019).

R:B.3.5+FR50 significantly increased the total fresh weight of the holy basil by 181 and $158 \%$ of R:B.3.5 and R:B.7. Of course pervious section clearly indicated that the leaf number and leaf area of the holy basil increase in very high percentage. This caused to increase the total fresh weight. Zhang et al. (2019) reported that the R:B with FR increased total plant 
biomass of tomato. Moreover, FR increased the total biomass of basil by adding FR $\left(30 \mu \mathrm{molm}^{-2} \mathrm{sec}^{-1}\right)$ to $\mathrm{R}: \mathrm{B}$ light more than without FR (Meng and Runkle, 2017). Tomato supplement by deep red+B+FR increased the shoot fresh weight (18.5\%) and the shoot dry weight $(15.4 \%)$ when compared to deep red+B without FR (Jiang et al., 2017). The total dry weight of holy basil under R:B.3.5+FR50 could increase dry weight by 147 and 92\% of R:B.3.5 and R:B.7 without FR.

What is interesting is that the FR radiation from phosphor-converted LED does not show the peak wavelength in the range of 700-800 nm but it emits a great amount of FR photon flux in this study which is around $25 \%$ of total photon flux. In comparison to many previous studies, the additional of FR into R:B light by using an external FR LED indicated the peak wavelength of 730-735 nm (Park and Runkle, 2017; Meng and Runkle, 2017; Zhen and Van Iersel, 2017; Islam et al., 2014). FR from external light or from pcHLED offered the similar results. The researchers summarized that the added FR could increase the leaf expansion, stem length, whole plant photosynthesis and total fresh weight/dry weight of the sweet basil and holy basil.

However, the R:B.3.5+FR50 from pcH-LED consumed the electric power less than R:B3.5 and R:B.7 which is about 48 and $40 \%$, respectively. This conveyed that the phosphor-converted LED for horticultural may be the future light source for plant factory and indoor farming. When dimming the phosphor-converted LED, the R:B and FR photo flux will change but the $\mathrm{R}: \mathrm{B}$ and $\mathrm{R}: \mathrm{FR}$ radiation ratios does not change. In the next study, the researchers would like to study the indoor plants yield per energy consumption $(\mathrm{kg} / \mathrm{kWh})$ under phosphor-converted LED enriched and R:B+FR.

\section{CONCLUSION}

Phosphor-converted LED for horticultural that researchers provided emitted big amount of FR included $\mathrm{R}$ and $\mathrm{B}$ light that appropriate for indoor horticultural. R:B lighting with FR increased leaf area, leaf number, radiation capture, growth rate, plant height, stem diameter and total fresh weight of the sweet basil and the holy basil with significantly higher than R:B combination without FR but it was non-effect to the leaf thickness of the crops.

\section{ACKNOWLEDGEMENTS}

The researchers would like to express appreciation to the National Research Council of Thailand who provided the budgets for this research (2017). Many thanks for Ponnapat Watjanatepin who proof reading the English usage in this study.

\section{REFERENCES}

Hao, X., C. Little, J.M. Zheng and R. Cao, 2016. Far-red LEDs improve fruit production in greenhouse tomato grown under high-pressure sodium lighting. Acta Hortic., 1134: 95-102.

Heliospectra, 2019. A study on the effects of Far-Red Enriched spectra on Lettuce. Heliospectra Company, Sweden.

Islam, M.A., D. Tarkowska, J.L. Clarke, D.R. Blystad, H.R. Gislerod, S. Torre and J.E. Olsen, 2014. Impact of end-of-day red and Far-Red light on plant morphology and hormone physiology of Poinsettia. Sci. Hortic., 174: 77-86.

Jiang, C., M. Johkan, T. Maruo, M. Hohjo, S. Tsukagoshi, M. Ebihara and A. Nakaminami, 2017. Effect of supplemental far-red light with blue and red LED lamps on leaf photosynthesis, stomatal regulation and plant development of protected cultivated tomato. Acta Hortic., 1227: 533-540.

Lumiled, 2017. LUXEON SunPlus series Lime LEDs produce high yield and nutrition in Leafy Greens. Lumileds Holding B.V., Amsterdam, Netherlands. https://www.digikey.com/en/pdf/l/lumileds/luxeo n-sunplus-lime-leds

Meng, Q. and E. Runkle, 2017. Far red is the new red: Adding far red to red and blue light from LEDs brings control of plant growth to the next level. Inside Grower, 2: 26-30.

Park, Y. and E.S. Runkle, 2017. Far-red radiation promotes growth of seedlings by increasing leaf expansion and whole-plant net assimilation. Environ. Exp. Bot., 136: 41-49.

Park, Y. and E.S. Runkle, 2018. Far-red radiation and photosynthetic photon flux density independently regulate seedling growth but interactively regulate flowering. Environ. Exp. Bot., 155: 206-216.

Taiz, L. and E. Zeiger, 2010. Plant Physiology. 5th Edn., Sinauer Associates, Massachusetts, USA., ISBN-13: 978-0878938667, Pages: 782.

Watjanatepin, N., H. Chung and C. Ruangpattanawiwat, 2018. Morphological response of tomato seedling under two periods of different red and blue photon flux ratio. Int. J. Adv. Applied Sci., 5: 22-27.

Zhang, Y.T., Y.Q. Zhang, Q.C. Yang and L.I. Tao, 2019. Overhead supplemental far-red light stimulates tomato growth under intra-canopy lighting with LEDs. J. Integr. Agric., 18: 62-69.

Zhen, S. and M.W. van Iersel, 2017. Far-red light is needed for efficient photochemistry and photosynthesis. J. Plant Physiol., 209: 115-122. 